\title{
SEXUALIDADE PRECOCE: UMA AÇÃO PEDAGOGICA NO ÂMBITO ESCOLAR E FAMILIAR
}

\author{
Márcia Gomes Inácio Vital ${ }^{1}$
}

RESUMO- O objetivo desse artigo é trazer definições do que é sexo e sexualidade, fazer uma reflexão sobre a sexualidade precoce e suas consequências, e quais tipos de prevenções devem ser feita. Conscientizar adolescentes e pais sobre a sexualidade precoce com uma ação educadora e preventiva no contexto escolar e familiar, pois é uma fase de descoberta para o adolescente e é fundamental a participação dos pais e da escola nesse processo. Para esse trabalho foi utilizado pesquisa bibliográfica em livros, artigos e outros. Como recursos para a pesquisa de campo serão feitas entrevistas com alunos em uma determinada escola. Para fundamentar este artigo foi recorrido a alguns autores como Bearzoti(2018), Belisse (2008), Beraldo(2003), Carneiro(2015), Freud(1937-1939), Gomes(2013), Maia(2010), Simões(2012), Souza(1999), entre outros.

Palavras- chave: Sexualidade. Adolescente. Escola. Família.

ABSTRACT - The aim of this article is to provide definitions of what sex and sexuality are, reflect on early sexuality and its consequences, and what types of prevention should be done. Raising awareness among adolescents and parents about early sexuality with an educational and preventive action in the school and family context, as this is a discovery phase for adolescents and the participation of parents and schools in this process is essential. For this work, bibliographical research in books, articles and others was used. As resources for the field research, interviews will be carried out with students in a specific school. To support this article, we resorted to some authors such as Bearzoti(2018), Belisse (2008), Beraldo(2003), Carneiro(2015), Freud(1937-1939), Gomes(2013), Maia(2010), Simões (2012), Souza(1999) among others.

Keywords: Sexuality. Adolescent. School. Family.

\footnotetext{
I Pós-Graduada em Psicopedagogia Institucional, Clínica e Educação Infantil: Faculdade Futura, mantida pelo Instituto de Ciência, Educação e Tecnologia de Votuporanga. Email: marciagomevital@gmail.com.
} 


\section{INTRODUÇÃO}

O presente artigo discorre sobre o tema "Sexualidade Precoce: Uma Ação Pedagógica no Âmbito Escolar e Familiar”, no enfoque da prevenção, da precocidade sexual, prevenção da gravidez na adolescência e doenças sexualmente transmissíveis (DSTs).

Brevemente será feita uma distinção de sexo e sexualidade, sexualidade precoce e quais as consequência, e como a escola e a família pode estar ajudando na prevenção de uma sexualidade precoce.

O público-alvo encontra-se em idades entre io e I6 anos, e demonstram estar entrando na puberdade, período esse que corresponde a mudanças hormonais, transformação do corpo e emocionais. Com isso foi observado curiosidade sobre esse tema, e comportamentos referentes a essa nova fase, levantam questões, falam sobre sexo, sobre namoro, parecem querer saber mais sobre o assunto, por isso a importância de falar sobre sexualidade.

O que se percebe, é que, embora os adolescentes estejam falando de namoro, sexo, falta ainda informações corretas, pois essas chegam de forma distorcida, e muitas vezes alguns, não tem maturidade para compreender e distinguir o certo do errado. Portanto, esses adolescentes precisam de orientação, para se conhecerem melhor, entenderem os limites do seu corpo, o aspecto emocional, o porquê dessa explosão de sentimentos, e a hora certa para iniciar sua vida sexual, para que saibam administrar e fazer escolhas certas. Ainda a importância de esclarecer que sexualidade é um assunto íntimo, e que não precisa se expor, nem expor os outros, mas buscar orientação com as pessoas certas.

Mesmo com o avanço que eles encontram nos dias de hoje sobre sexualidade, para alguns pais falar sobre isso, ainda é um tabu, visto que, por vezes eles não receberam devida orientação, não sabem ou não ficam à vontade para falar sobre isso, o que ocasiona a vulnerabilidade das crianças.

Através da observação feita na escola, foi possível ver crianças dançando ao som de músicas que fazem apologia ao sexo com uma linguagem inapropriada para suas idades, além disso as coreografias que realizavam, lembravam movimentos realizados durante atos sexuais e muitas vezes são influenciadas pelos próprios adultos. 
Então notou a necessidade de explanar esse assunto, orientando e prevenindo tanto os adolescentes quanto aos pais e professores da real importância de fazer chegar até esses garotos as informações corretas e precisas para cada idade.

Ao trabalhar com a sexualidade a escola deve ter uma posição clara do que pretende. O assunto é complexo e envolve não só o professor e o aluno, mas também sua família. Um bom embasamento teórico é fundamental, para se colocar a sexualidade num contexto amplo, ligado a vida e a afetividade, para não se tornar frágil e improdutivo.

Para iniciar as discussões sobre sexualidade precoce se faz necessário uma clara distinção entre o que é sexo e o que é sexualidade. No tópico abaixo alguns autores explanaram o que é sexo, e o que é sexualidade.

\section{DIFERENÇA ENTRE SEXO E SEXUALIDADE}

Para iniciar as discussões sobre sexualidade se faz necessário uma clara distinção entre o que é sexo e o que é sexualidade.

De acordo com Rios (2010), Sexo significa, “conformação característica que distingue o macho da fêmea, nos animais e vegetais, os órgãos sexuais externos, sensualidade, volúpia". Portanto, a "Sexualidade significa, qualidade de sexual, conjuntos dos caracteres especiais do que tem sexo e instinto sexual “(p. 473).

Para os autores Senem e Caramaschi (2017), a palavra sexo é usualmente utilizada para distinguir a mulher do homem, o sexo feminino do masculino. Ela possui referencial fisiológico e está diretamente relacionada aos órgãos sexuais e à anatomia dos corpos, assim como também é utilizada para se referir ao ato sexual. O sexo possui características filogenéticas sendo formado ao longo de toda evolução da espécie humana como ser animal e reconhecido pela genitalidade. (p. 166)

Senem e Caramaschi (2017) declara que a Sexualidade foi um conceito que surgiu apenas no século XIX sendo utilizado para representar a qualidade e a significação do que é sexual, ampliando assim a ideia de sexo. E que Freud foi um dos primeiros pensadores que concebeu a sexualidade como um fenômeno diferente do sexo. Ele expandiu o conceito de sexualidade para além do ato sexual ou de qualquer vínculo exclusivo com a reprodução ou com os órgãos genitais. 
Segundo Senem e Caramaschi (2017) apud OMS (2006), expressão que a definição de sexualidade proposta pela Organização Mundial de Saúde (OMS) é:

Um aspecto central do ser humano ao longo da vida e engloba sexo, identidades e papeis de gênero, orientação sexual, erotismo, prazer, intimidade e reprodução. A sexualidade é vivida e expressa em pensamentos, fantasias, desejos, crenças, atitudes, valores, comportamentos, práticas, papeis e relacionamentos. Enquanto a sexualidade pode incluir todas essas dimensões, nem todas elas são sempre vivenciadas ou expressas. A sexualidade é influenciada pela interação de fatores biológicos, psicológicos, sociais, econômicos, políticos, culturais, legais, históricos, religiosos e espirituais (OMS, 2006).

Para Souza (1999) “a sexualidade é algo natural, presente em todas as pessoas: crianças, jovens, adultos e idosos. Ao mesmo tempo está cercada de repressões, valores diversos, preconceitos que afetem essa energia espontânea, pois é algo importante no comportamento humano" (p.45).

Segundo Britzman o significado da palavra sexo originária do latim sexu, consiste na "conformação particular que distingue o macho da fêmea, nos animais e nos vegetais, atribuindo-lhes um papel determinado na geração e conferindo-lhes certas características distintivas que diz respeito, aos aspectos biológicos apenas. Portanto, podemos entender, que sexo é diferente de sexualidade(I999).

Britzman (1999), destaca que Foucault nos propicia uma outra forma de pensar sobre a sexualidade, não como desenvolvimento ou identidade mas como historicidade e relação. A sexualidade não deve ser pensada como um tipo de dado natural que o poder tenta manter sob o controle, ou como um obscuro domínio que o conhecimento tenta gradualmente descobrir. Ela é o nome que pode ser dado a um construto histórico, não uma realidade furtiva que é difícil de apreender, mas uma enorme superfície em forma de rede na qual as estimulações dos corpos, a intensificação dos prazeres, o incitamento ao discurso, a formação de um conhecimento especializado, o reforço de controles e resistências estão vinculados uns aos outros, de acordo com algumas poucas estratégias importantes de saber e poder (1999).

Portanto, o sexo e a sexualidade são entendidos como algo inerente, que se manifesta desde o momento do nascimento até a morte. E contudo, a sexualidade é construída ao longo da vida, encontra-se necessariamente marcada pela história, cultura, ciência, assim como pelos afetos e sentimentos expressando-se então com singularidade em cada sujeito. 


\section{SEXUALIDADE PRECOCE, ESCOLA E FAMÍLIA}

Neste tópico aprofundaremos mais sobre a sexualidade e as prevenções de uma sexualidade precoce, e como a escola e a família pode estar contribuindo nesse processo.

Freud(1937-1939) diz que a sexualidade é algo de conceituação complexa, e vem sendo alvo de tabus, repressões e distorções. No senso comum a sexualidade é conceituada como sinônimo de genitalidade e de reprodução. Freud diz que sexualidade vai além da reprodução e que os impulsos sexuais estão presentes desde o recém-nascido, propondo um modelo enérgico, conceituando sexualidade como energia (FREUD,1937-1939).

Segundo o autor Bearzoti (1993) podemos conceituar a sexualidade como uma energia vital instintiva direcionada para o prazer, passível de variações quantitativas e qualitativas, vinculada à homeostase, à afetividade, às relações sociais, às fases do desenvolvimento da libido infantil, ao erotismo, à genitalidade, à relação sexual, à procriação e à sublimação.

Como vimos à sexualidade é vista a partir de três aspectos: biológico, psicológico e social. Portanto, não dá para falar de sexualidade voltada apenas para o campo sexual (corporal). Ou seja, há uma necessidade de olhar para o psíquico e social, de forma que os três aspectos não podem ser isolados.

D `ALAMA (2013), afirma que é de grande importância que os pais e a escola estejam na mesma sintonia a respeito da sexualidade, pois quanto mais a criança se aproxima da adolescência, despertam questionamentos cada vez mais elaborados de acordo com a idade, além das mudanças do corpo, questões sobre o sexo, camisinha, gravidez e doenças sexualmente transmissíveis, menarca (primeira menstruação), masturbação, desejo, excitação, sexo oral e anal, orgasmo, primeira ejaculação espontânea. Diz ainda que na fase da adolescência os jovens estão enfrentando difíceis dilemas como: sexual, profissional, existencial e tóxico (2013).

Beraldo (2003) diz que a educação sexual acontece no contexto familiar baseado em seus valores, religiões. A orientação sexual cabe à escola, mostrando os direitos a valorização e conhecimento sexual, de maneira científica e desmistificadora.

Feitosa e Calou destacam que, cabe à escola abordar os diversos pontos de vista, valores e crenças existentes na sociedade para auxiliar o aluno a encontrar um ponto de auto referência por meio da reflexão. Nesse sentido, o trabalho realizado pela escola, denominado aqui de Educação Sexual, não substitui nem concorre com a função da família, mas antes a 
complementa. Constitui um processo formal e sistematizado que acontece dentro da instituição escolar, exige planejamento e propõe uma intervenção por parte dos profissionais da educação. (2011, p. 34).

Ainda temos em nossa sociedade dados graves sobre gravidez precoce, que pode acontecer, por falta de informação, falta de comunicação com a família. Belisse (2008) relata que a gravidez na adolescência é um resultante de falta de informação, de medo de assumir a vida sexual e da falta de espaço para discussão de valores no meio familiar.

Outro perigo que pode ocorrer é sensação de poder que os adolescentes têm, acham que são invencíveis, e que nada de mal vai acontecer com eles, o que pode gerar consequências indesejáveis. Consequentemente, a sexualidade precoce pode trazer consequências como doença sexualmente transmissíveis ou gravidez precoce:

Gomes (2013), enfatizando-se mecanismos para prevenção de DSTs /Aids e gravidez precoce como objetivo principal de ações de educação para saúde, deve-se desconsiderar que esses são meramente fatos reveladores da consequência de uma precocidade, imaturidade e, por que não dizer, até mesmo violação, a que se submetem quando antecipam a atividade sexual para a qual ainda não estão preparados, nem têm segurança e responsabilidade para tal, visto que a maturação corporal precede à psicoemocional. (p.I03).

A gravidez na adolescência, é também resultado de uma infância submetida à negligencias de informações e exposições a condições de extrema vulnerabilidades, no qual fica propicio a esses fatores, no qual passa a ser obrigado a ter responsabilidades de seu próprio corpo e também por outra pessoa que será agora dependente deste adolescente como afirma Carneiro (2015):

A gravidez na adolescência resulta no ingresso na vida adulta. Mesmo sem preparo psicológico, as jovens são forçadas a mudar completamente seu modo de vida, [...], resultante da falta de educação sexual, de planejamento familiar e da adoção incorreta de métodos contraceptivos. Outro problema que merece atenção são as DST na adolescência, pois devido ao seu aparecimento, podem gerar risco de infertilidade, de gravidez ectópica, de câncer genital e até doença hepática crônica" (CARNEIRO et al, 2015, p. 105).

A autora Belissa, (2008), fala que na adolescência os jovens possuem um pensamento mágico de proteção e invulnerabilidade, daquele tipo que comigo não ocorre, mas que geralmente traz consequências desagradáveis e desastrosas, não só para eles.

Segundo Simões (2012), ainda hoje a sexualidade é um assunto cercado de dificuldades, tabus e preconceitos, seja na área profissional escolas e consultórios ou pessoal (relacionamentos entre pais e filhos, namorados, casais, parceiros sexuais). É frequente as pessoas associarem sexo à "safadeza", "falta de vergonha", 
“imoralidade”, “pecado”. Uma grande parte das pessoas não teve, quando jovens, oportunidade de conversar sobre sexo com seus pais.

Assim sendo, é difícil evitar o início da vida sexual precoce. Mas os adolescentes que conversam mais em casa e na escola e que têm informação, tendem a começar mais tarde do que aqueles que estão desamparados, que não têm família que os apoiam, que não estão na escola e que têm uma condição socioeconômica mais precária. Maia diz que, as mudanças físicas têm um significado importante para o adolescente, e o fato de lidar com essas mudanças pode gerar conflitos emocionais diante de uma imagem corporal nova e desconhecida, como por exemplo sentimentos de baixa auto-estima e sintomas depressivos. Quando as transformações biológicas não são bem compreendidas, o adolescente pode sentir medo, vergonha e ansiedade (MAIA, 2010).

\section{Método e Resultados}

Inicialmente faremos uso de pesquisa bibliográfica em leitura específica, e sites acadêmicos. Como recursos para a pesquisa de campo serão feitas entrevistas na escola, tanto os pais quanto os adolescentes e educadores, através dessas entrevistas, serão aplicadas atividades reflexivas que possibilitarão ao público-alvo perceber como pensa e sente a sociedade à sua volta em relação a sexualidade precoce.

A pesquisa será de natureza qualitativa. Este tipo de pesquisa preocupa-se com o universo de significados, motivos, aspirações, atitudes, entre outros, estabelecendo as ações e relações entre pais, filhos e educadores.

Essa pesquisa contará com adolescentes com faixas etárias de IO a I4 anos, pais ou responsáveis e educadores, que atuam na educação desta escola.

Para proceder à coleta de dados, foi utilizada a técnica de entrevista, com alunos, pais e educadores. Esse processo se deu da seguinte forma: duração de 3 meses, I vez na semana, com duração aproximadamente de 30 minutos. Para a entrevista foi usado um questionário, com perguntas relacionadas ao tema como: o que é sexo? O que é sexualidade? O que é abuso sexual? Como é a relação dos pais e filho sobre o tema proposto? A escola faz prevenção sobre gravidez precoce, doenças sexualmente transmissíveis e abuso sexual?

Contudo, a entrevista não se deu de uma forma limitada, com respostas rápidas e precisas. Entre as questões foi dada a liberdade para o entrevistado (a) abordar um pouco 
mais sobre o assunto, e até temas relacionados ao mesmo. Em alguns pontos notou-se informalidade na entrevista, que se fez necessária para o mapeamento. Foi através dessa informalidade e observação, que foi delimitado o tema sexualidade precoce.

A maioria dos entrevistados foram do sexo feminino, ao final da coleta de dados foram selecionados os temas com mais ênfase. Os temas mais argumentados na pesquisa de campo foram: Sexualidade precoce, gravidez precoce, doenças sexualmente transmissíveis, abusos sexuais e drogas. Sendo que, o tema mais denotado foi a sexualidade precoce.

Foram realizadas duas formas de palestras. A primeira foi destinada aos adultos (pais, educadores escolares), e a segunda para crianças e adolescentes de io a I4 anos.

O que determinou a tomada de decisão sobre como realizar essa intervenção foi a linguagem usada e o tipo de orientação que se deve passar para cada grupo, de modo que, ao falar com crianças e adolescentes se usa um discurso menos direto tomando o devido cuidado para não ultrapassar seu limite de compreensão e pela delicadeza do assunto.

Já para os pais e educandos o discurso mais direto, abordando o tema sem adornos, orientando a prevenção e as consequências de uma sexualidade precoce, sendo que nessa fase não estão preparados fisicamente e nem psicologicamente, podendo assim trazer prejuízos em seu desenvolvimento físico, biológico, mental, escolar e familiar.

\section{CONCLUSÃO}

Diante destes esclarecimentos sobre o tema sexualidade precoce, espera-se que alunos, pais e professores reflitam um pouco mais sobre seus atos e que haja uma sensibilização acerca do tema proposto a eles.

Vimos que, através do incentivo aos profissionais e aos pais o fato de fomentar sobre sexualidade precoce aos alunos os deixam esperançosos, pois acreditam que a informação e a instigação podem trazer resultados positivos diante de alguns problemas que enfrentam com os adolescentes.

Mudar a visão dos adultos de que a sexualidade não deve ser vista como assunto vergonhoso e desrespeitoso, e apresentando os benefícios de trazer esse assunto dentro de casa e em sala de aula. 
A relevância do tema trabalhado se dará a partir do momento que nós enquanto comunidade escolar pudermos observar e verificar que foi positivo o trabalho realizado.

Portanto, a escola possui um papel muito importante na transmissão de conhecimentos e que cumprirá dia após dia sua verdadeira função, existe um empenho por parte da equipe escolar para que este projeto não se encerre, pois verificamos que o trabalho realizado durante o ano letivo foi produtivo.

É importante salientar que, o que mais proporcionou satisfação neste trabalho é a contribuição para conscientizar os envolvidos de algo tão importante para a qualidade de vida dos mesmos, e que há muito que fazer na escola em relação à Educação Sexual. Uma certeza permanece a de que foi lançada uma semente que poderá no futuro produzir bons frutos.

\section{REFERÊNCIAS}

BEARZOTI, Paulo. Sexualidade: Um conceito Psicanalítico Freudiano. Av. Andrave Neves 784, conj. B-4 -13013-16I, Campinas SP - Brasil, agosto-1993. Disponível em: http://www.scielo.br/pdf/anp/v52nI/24. Acesso em: 25 de fevereiro de 2018.

BELISSE, Claudia Leila. Atividade Sexual Precoce na adolescência: a importância da educação sexual nas escolas. Professora de ciências/biologia da Rede Estadual de Educação do Paraná. Participante do Projeto de Desenvolvimento Educacional (PDE) desenvolvimento pela SEED/ PR. 2008.

BERALDO, Flávia Nunes de Moraes. Sexualidade e escola: um espaço de intervenção. Psicol. Esc. Educ. (Impr.), vol.7 no.I, Campinas. Junho 2003. Disponível em: http://dx.doi.org/ro.1590/Si413-85572003000I00012. Acesso em: o6 de abril de 2021.

BRITZMAN, Deborah. O corpo educado: pedagogias da sexualidade. Curiosidade, sexualidade e currículo. In: LOURO, Guacira Lopes (Org.). Belo Horizonte: Autêntica, 1999. p. 83-III.

CARNEIRO, Rithianne Frota et al. Educação Sexual na Adolescência: Uma Abordagem no Contexto Escolar. S A N A R E, Sobral, V.I4, n.or, p.Io4-1o8, jan./jun. - 2015.

D'ALAMA, Luna. Saiba como falar sobre sexo em cada idade na faixa de o a 17 anos. Do Gi, em São Paulo. Atualizado em io junho de 2013 às oghı6. Disponível em: < http://gi.globo.com/bemestar/noticia/2013/o6/livro-mostra-como-falar-de-sexo-em-cadaidade-na-faixa-de-o-I7-anos.html $>$. Acesso em 04 de maio 202I. 
FEITOSA, Cícera Honório. CALOU, Virgínia Torquato. EDUCAÇÃO SEXUAL: ALGUMAS REFLEXÕES. Id on line Revista de Psicologia. Ano 5, No. 13, Fevereiro/20II ISSN 198I-II79.

FREUD, Sigmund. Moisés e o monoteísmo, Esboço de Psicanálise e outros trabalhos. Imago 1937-1939. Vol. XXX111.

GOMES, Claudia de Morais. Vivencia em Grupo: Sexualidade, Gênero, Adolescência e Espaço Escolar. Rev APS. jan/mar; I6(I): I03-III, 2013

MAIA, Ana Cláudia Bortolozzi. Conceito Amplo de Sexualidade. Psicóloga; Mestre em Educação Especial (UFSCar) e Doutora em Educação (UNESP/Marília) Departamento de Psicologia/ Faculdade de Ciências/ UNESP/Bauru, Pós-Graduação em Psicologia do Desenvolvimento e da Aprendizagem/UNESP/Bauru, outubro 2010.

RIOS, Dermival Ribeiros. Minidicionário escolar da língua português. São Paulo: DCL, 2010.

SENEM, Cleiton José. CARAMASCHI, Sandro. Concepção De Sexo E Sexualidade No Ocidente: Origem, História E Atualidade. Barbarói, Santa Cruz do Sul, n.49, p., jan./jun. 2017 .

SIMÕES, Renata Nunes. Sexo, sexualidade e orientação sexual. Copyright Moreira Jr.

Editora. Todos os direitos reservados. Pediatria Mordena Jan I2 v 48 n I, 2012.

SOUZA, Hália P. Auliv de. Orientação Sexual: Conscientização, Necessidade e Realidade. I ${ }^{a}$ ed., 2 $2^{\underline{a}}$ tir. Curitiba: Juruá, I999. 